\title{
QUATRO DÉCADAS DE INSTITUCIONALIZAÇÃO DO DISCURSO AMBIENTAL: lógicas integrativas e restaurativas em currículos educativos
}

\author{
Francisca Marli Rodrigues de Andrade ${ }^{1}$
}

Fábio Alves Gomes de Oliveira²

A história do discurso ambiental, tal como hoje a conhecemos -com forte viés antropocêntrico-, está marcada por lutas travadas pela sociedade civil em defesa do ambiente, intensificadas a partir dos anos de 1960. As discussões fomentadas pelos movimentos ambientalistas tinham como finalidade a melhoria das condições de vida na Terra, pautada em uma perspectiva ecológica; ou seja, a harmonia entre ser humano e natureza (LEIS; D’AMATO, 1995). Neste sentido, o ambientalismo, surge como causa e efeito de uma importante mudança de mentalidade, que "tinha no pacifismo e na oposição ao nuclear os seus principais tópicos" (REIGOTA, 2011, p. 35). Questões relativas à poluição ambiental, o uso desmedido de produtos químicos tóxicos em consonância ao uso da tecnologia à serviço de um pensamento bélico forjava o que a autora Rachel Carson chamou de ação biocida (CARSON, 2010).

Diante deste cenário, formou-se em diferentes países uma expressiva mobilização social em defesa do ambiente, onde ideais ambientalistas e preservacionistas foram difundidos em âmbito internacional. Difusão esta que impôs aos chefes de Estado e aos organismos internacionais a necessidade de reafirmar a sua condição de poder e, portanto, o disciplinamento dos saberes. Tal disciplinamento, desde a compreensão de Foucault (2003, p. 157), opera por meio de quatro procedimentos básicos: "seleção, normalização, hierarquização e centralização". Deste modo, a voz "oficial”, por meio de textos e documentos originados principalmente dos grandes eventos internacionais, estabeleceu a ordem do discurso ambiental em diversos espaçostempos da sociedade. Entre eles, os currículos educativos escolares, bem como todas as produções e representações pensadas e projetadas nas diferentes esferas educativas.

Resgatamos as discussões sobre o discurso ambiental nas esferas institucionais para situar que estas se iniciaram com a realização da Conferência das Nações Unidas sobre o Ambiente Humano, celebrada em Estocolmo-Suécia em 1972. O principal resultado deste encontro constituiu-se na Declaração sobre o

${ }^{1}$ Professora Adjunta na área de Saúde e Meio Ambiente, vinculada ao curso Interdisciplinar em Educação do Campo Departamento de Ciências Humanas da Universidade Federal Fluminense (UFF). Possui doutorado em Educação, Cultura da Sustentabilidade e Desenvolvimento pela Universidade de Santiago de Compostela (USC) - Espanha. Colabora com redes de pesquisas em âmbito nacional e internacional. É membro titular da Comissão Permanente de Sustentabilidade da Universidade Federal Fluminense (CPS) e da Comissão de Assessoramento para o Planejamento, Implementação, Acompanhamento e Avaliação das Ações vinculadas ao Projeto Redes de Educação e Sustentabilidade da Universidade Federal Fluminense (UFF). Forma parte do Grupo Encontro de Saberes na UFF, vinculado ao Instituto Nacional de Ciência e Tecnologia da Inclusão (INCTI) com sede na Universidade de Brasília (UnB). E-mail: <marli_andrade@id.uff.br>

2 Fabio A. G. Oliveira é professor adjunto de Filosofia da Educação junto ao Departamento de Ciências Humanas da Universidade Federal Fluminense (UFF); membro permanente do Programa de Pós-Graduação em Bioética, Ética Aplicada e Saúde Coletiva (PPGBIOS) da UFF, atuando na linha de pesquisa de Ética Animal e Ambiental; e colaborador externo do Programa de Pós-Graduação em Filosofia (PPGF) da Universidade Federal do Rio de Janeiro (UFRJ), atuando nas linhas de pesquisa de Filosofia Prática; e Gênero, Raça e Colonialidade. Coordena o Laboratório de Ética Ambiental e Animal (LEA); é integrante da Sociedade Portuguesa de Ética Ambiental; e membro do Instituto Latinoamericano de Estudios Críticos Animales (ILECA). É autor da obra "Responsabilidade Individual Frente às Mudanças Climáticas Globais" (2015) e organizador do livro "Ética Animal: Um Novo Tempo" (2018). 
Ambiente Humano, na qual é expressa a convicção de que tanto as gerações presentes como as futuras tenham reconhecido como direito à vida num ambiente saudável e não degradado (CARIDE; MEIRA, 2001). Deriva-se desta percepção do direito a um ambiente de qualidade inúmeros trabalhos em torno da ética aplicada, do direito ambiental e, em especial, do conceito de responsabilidade aplicado às gerações presentes e futuras. Em outras palavras, foram delineados os principais elementos que, para Moll (1991), nos levam da escassez à sustentabilidade. Porém, para Sampaio e Guimarães (2012), estes elementos estabelecem e sustentam o dispositivo da sustentabilidade, os quais instituem e molduram as formas de pensar e agir.

Nas sutilezas do pensar e agir, a dimensão ambiental, associada às práticas educativas, foi amplamente discutida e pontuda na Declaração de Tbilisi, como resultado da Primeira Conferência Intergovernamental sobre Educação Ambiental, celebrada na cidade de Tbilisi, antiga URSS, em 1977. Após quatro décadas de institucionalização do discurso ambiental voltado à educação, temos acompanhado diferentes associações às múltiplas experiências de aprender-ensinar nos espaçostempos educativos. Isto é, às diferentes compreensões de currículo que caracterizam o resultado do acúmulo das experiências de aprender-ensinar em âmbito institucional educativo escolar e fora dele. Este acúmulo de experiências ressignifica a afirmativa de que "o currículo é lugar, espaço, território. O currículo é relação de poder. O currículo é trajetória, viagem, percurso. O currículo é autobiografia, curriculum vitae: no currículo se forja nossa identidade. O currículo é texto, discurso, documento. O currículo é documento de identidade" (SILVA, 2011, p. 150).

A partir da compreensão de currículo anteriormente citada e das críticas tecidas à institucionalização do discurso ambiental nos diferentes espaços educativos, apresentamos esta sessão temática da Revista Espaço do Currículo (REC) sob o título QUATRO DÉCADAS DE INSTITUCIONALIZAÇÃO DO DISCURSO AMBIENTAL: lógicas integrativas e restaurativas em currículos educativos. A referida sessão tem como finalidade promover o encontro entre diferentes diálogos e debates e, portanto, resgatar algumas pautas e atores, cujas vozes historicamente estiveram silenciadas no campo epistemológico ambiental. Esses diálogos e debates contemplam as temáticas que estão associadas à configuração integrativa e restaurativas do discurso ambiental atual, vinculadas as práticas educativas escolares e não escolares. Ambas lógicas integrativa e restaurativas- não se configuram como algo excludente, ao contrário, se inscrevem nas duas perspectivas, reciprocamente.

Com estes princípios -integrativo e restaurativo- os trabalhos que conformam este número desafiam as expressões e compreensões de currículo, na mesma medida em que questionam a posição das escolas, das universidades e de outros espaços educativos ao repensar o ambiente desde diferentes epistemologias, atores sociais, natureza e animais não-humanos na condição de sujeitos de direitos. Confrontam, portanto, "os cenários de produção de inexistências da realidade, de saberes e de práticas locais que sucumbem diante do fortalecimento dos mecanismos de reprodução cultural" (ANDRADE; CARIDE, 2017, p. 1615). Nesse sentido, este número da Revista Espaço do Currículo (REC) lança o desafio em sentido da necessária refundação do campo teórico, metodológico e epistemológico ambiental. Nesta refundação, cada uma das autoras e dos autores, reconhecidos em seus campos de pesquisas, apresentam os elementos desestruturantes das lógicas hegemônicas e, ao tempo, revelam outras possibilidades nos âmbitos da pesquisa, das práticas sociais e comunitárias, da formação profissional e no exercício da cidadania.

Com esses horizontes, a organização deste número da Revista Espaço do Currículo (REC) contempla vinte artigos e uma resenha. Está estruturada em cinco blocos temáticos, os quais representam o acúmulo de experiências desenvolvidas pelas pesquisadoras e pelos pesquisadores do campo ambiental. Tais profissionais pertencem a diferentes contextos de pesquisa e, portanto, nos presenteiam oportunidades únicas de repensar a relação ambiente e sociedade, sobretudo em tempos de injustiças, racismo e barbárie ambiental. Em diferentes espirais, as autoras e os autores agregam suas perspectivas e interpretações da realidade, os atravessamentos do campo e suas possíveis mudanças. Os diálogos e debates promovidos com este número, e a partir dele, oferecerá aos leitores outras abordagens do discurso ambiental. Todas elas inscritas na possibilidade de questionar o eurocentrismo, o colonialismo e o capitalismo enquanto ferramentas de dominação da natureza, de humanos e não-humanos. 
ISSN 1983-1579

http://periodicos.ufpb.br/ojs2/index.php

O primeiro bloco reúne cinco artigos que dialogam em sentido de promover a crítica ao discurso ambiental hegemônico e, portanto, o confrontam desde outras perspectivas epistêmicas, sobretudo das teorias decoloniais. No primeiro artigo, EDUCAÇÃO AMBIENTAL EM MIRADAS INTEGRATIVAS E RESTAURATIVAS: currículos educativos na Amazônia, produzido por Francisca Marli Rodrigues de Andrade Universidade Federal Fluminense (UFF)-, a autora oferece aos leitores discussões inscritas nas representações de currículo na Amazônia. Para isto, ressalta o distanciamento que caracteriza o modo como as políticas públicas educativas em Educação Ambiental são pensadas e implementadas nas escolas da região amazônica. Investiga os desafios encontrados pelos docentes para dialogarem com a realidade, recorrerem às lógicas integrativas e restaurativas e, assim, contextualizam a história, a cultura e a vida amazônica. Entre os principais resultados, a autora destaca o surgimento de um movimento social entre os docentes que questionam as concepções naturalistas de ambiente e, portanto, reivindicam outras lógicas frente ao currículo e aos desafios ambientais impostos à região.

O segundo texto, de autoria de Taís Cristine Ernst Frizzo e Isabel Cristina de Moura Carvalho -ambas da Universidade Federal do Rio Grande do Sul (UFRGS)-, com o título TÃO PERTO E TÃO LONGE: escolas próximas a unidades de conservação e os desafios para a ambientalização do currículo, as autoras estabelecem um diálogo entre escolas e unidades de conservação em Porto Alegre e Viamão, RS. Apresentam, nesse sentido, os aspectos que motivam ou que dificultam as relações entre ambas instituições, bem como as relações que influenciam o processo de ambientalização do currículo escolar. Destacam, entre outros aspectos, os limites de algumas políticas públicas educacionais, as imposições referentes as regras de acesso e uso das unidades de conservação e, especialmente, os conflitos históricos que caracterizam a implementação desta instituição no país. Entre os principais resultados, as autoras reafirmam a valorização de todas as formas de vida e de saberes e, por isso, apostam no estreitamento das relações entre escolas e unidades de conservação, enquanto possibilidade de ampliar a Educação Ambiental para além das áreas protegidas.

Sandra Maders e Valdo Barcelos -Universidade Federal do Pampa (UNIPAMPA) e Universidade Federal de Santa Maria (UFSM), respectivamente-, brindam aos leitores a possibilidade de dialogar com o artigo EDUCAÇÃO AMBIENTAL E INTERCULTURA: pensando um currículo a partir dos trópicos. O referido trabalho tem como objetivo promover a reflexão sobre as possibilidades de construção de conhecimentos curricular numa perspectiva intercultural. O texto é tecido com base nas contribuições de dois pressupostos epistemológicos da obra de Humberto Maturana: a Biologia do Amor (BA) e a Biologia do Conhecimento (BC), bem como as proposições filosóficas da Antropofagia Cultural Brasileira (ACB) para a construção de uma educação ambiental (EA) a partir dos trópicos. Com esses pressupostos, Sandra e Valdo elaboram críticas à prática de copiar, na mesma medida em que destacam as potencialidades da Educação Ambiental dos trópicos enquanto possibilidade e romper com a prática subalternizante de imitar modelos sem a devida contextualização.

Sob o título AS CONTRIBUIÇÕES DOS CONHECIMENTOS TRADICIONAIS INDÍGENAS PARA A EDUCAÇÃO AMBIENTAL BRASILEIRA, Elisangela Castedo Maria do Nascimento e Heitor Queiroz de Medeiros -ambos da Universidade Católica Dom Bosco (UCDB)-, enriquecem o diálogo ao sistematizarem contribuições teóricas sobre a Educação Ambiental na pós-colonialidade. Para tanto, articulam uma discussão voltada aos saberes ancestrais indígenas e ao conceito de Ecologia de Saberes. Em outras palavras, uma tentativa de entender os tropeços da Ciência Moderna em relação ao ambiente e à cultura indígena. Recorrem, nesse sentido, às contribuições das teorias Pós-Coloniais e dos Estudos Culturais para a construção de uma Educação Ambiental pautada na valorização dos conhecimentos tradicionais. Desta forma, problematizam e propõem a crítica ao desenvolvimento da ciência, em sentido de razão e poder, especialmente quando pensada como resposta a todos os problemas da humanidade.

O texto A INSERÇÃO DA EDUCAÇÃO AMBIENTAL CRÍTICA NA ESCOLA VIA EXTENSÃO UNIVERSITÁRIA, apresentado por Maira Rocha Figueira, Maria Jacqueline Girão Soares de Lima e Sandra Lucia Escovedo Selles 
-Prefeitura Municipal de Maricá (PMM), Universidade Federal do Rio de Janeiro (UFRJ) e Universidade Federal Fluminense (UFF), nesta ordem-, resgata a inserção da Educação Ambiental em duas escolas do Rio de Janeiro. Para o desenvolvimento da pesquisa, as autoras apostaram no potencial da extensão para o fortalecimento da Educação Ambiental crítica na escola. De igual maneira, para a promoção de diálogos e troca de saberes entre os sujeitos das instituições envolvidas, justamente com o propósito de buscar a superação das realidades socioambientais. Entre os principais resultados, as autoras destacam as concepções voltadas a três macrotendências da Educação Ambiental (conservacionista, pragmática e crítica). Nesse sentido, enfatizam que, ao ser recontextualizada na escola, a Educação Ambiental apresenta uma mescla de concepções, mobilizadas de acordo com diversas demandas escolares.

O segundo bloco contempla quatro artigos que visam a destacar e problematizar o caráter antropocêntrico ainda presente nas discussões ambientais mais conservadoras. Para tal, os trabalhos deste bloco se associam às bases conceituais interdisciplinares da bioética e ética aplicada para, então, postular questionamentos acerca dos fundamentos éticos-políticos clássicos que deslocaram o antropocentrismo das discussões ambientais. Desta maneira, os textos enfrentam o antropocentrismo como parte de um projeto ecocida. Neste processo, o ambiente e os animais não-humanos são convocados para o centro da discussão ético-política e socioambiental, com a finalidade de defender a necessidade de uma educação anti-especista, fruto de uma concepção de moralidade expandida. Nota-se neste bloco a defesa das questões ambientais e animais como tópicos integrantes de um projeto de justiça social mais abrangente (OLIVEIRA, 2018).

O artigo EDUCAÇÃO, ÉTICA ANIMAL E AMBIENTAL: destituindo o paradigma antropocêntrico, de autoria de Maria Clara Dias e Fabio Alves Gomes de Oliveira -Universidade Federal do Rio de Janeiro (UFRJ) e Universidade Federal Fluminense (UFF), respectivamente, propõe uma fundamentação filosófica através da apresentação de conceitos básicos convergentes da ética animal e ambiental, de modo a identificar a questão relativa ao valor relacional presente no debate ambiental. A partir de um olhar diferenciado sobre o lugar dos animais e do ambiente, os autores defendem uma proposta filosófico-pedagógica que assuma o papel de questionar as diversas formas de injustiças cometidas contra animais e ambiente e, ao mesmo tempo, defenda a noção de razão imaginativa - esta última capaz de estimular os indivíduos a refletirem sobre a relação humano- ambiente e humano-animal de forma mais empática. A empatia como projeto ético de sensibilização moral se acomodaria à educação através não somente da revisão dos conteúdos programáticos, mas da introdução de recursos visuais, tais como filmes e fotografias.

UMA BIOÉTICA AMPLIADA PARA A INCLUSÃO DE REFLEXÕES SOBRE QUESTÕES ANIMAIS E AMBIENTAIS, de autora de Tânia Aparecida Kuhnen -Universidade Federal do Oeste da Bahia (UFOB)-, visa a apresentar os problemas ambientais como uma discussão iminentemente bioética. Kuhen defende, ao longo de seu trabalho, uma concepção ecofeminista de bioética que permite pensar uma educação ambiental crítica. Precisamente, uma perspectiva que rompa com os dualismos hierárquicos de valor e que, consequentemente, incentive novos modos de se relacionar com outras formas de vida de maneira não opressiva e destrutiva. Com isso, a autora pretende dar sentido pleno a ideia de preservação da natureza, através de uma concepção de bioética como um espaço de conscientização que proponha um novo lugar para o ser humano em relação a outras formas de vida.

O artigo VISÕES DOS ESTUDANTES DE BIOLOGIA SOBRE QUESTÕES ÉTICAS ANIMAIS E AMBIENTAIS, de autoria de Lucas Nascimento Ferreira Lopes, doutorando do Programa de Pós-Graduação em Bioética, Ética Aplicada e Saúde Coletiva (PPGBIOS) da Universidade Federal Fluminense (UFF) e Carlos Ribeiros Martins Dimas, da Universidade Federal Fluminense (UFF), apresenta o resultado de entrevistas semiestruturadas com estudantes de graduação em Biologia com o intuito de observar as problemáticas dentro da formação do biólogo, no que se refere às temáticas animal e ambiental. Com o propósito de suscitar discussões acerca do perfil profissional do biólogo, o trabalho sugere a necessidade de uma revisão profunda sobre como questões ambientais e animais estão inseridas no processo de formação dos estudantes do curso de biologia.

O PROBLEMA DA AUSÊNCIA DA BIOÉTICA NO CURRÍCULO DOS CURSOS DE CIÊNCIAS BIOLÓGICAS 
ISSN 1983-1579

http://periodicos.ufpb.br/ojsz/index.php

NO BRASIL, artigo de Gabriela Bertti da Rocha Pinto, doutoranda do Programa de Pós-Graduação em Bioética, Ética Aplicada e Saúde Coletiva (PPGBIOS) da Universidade Federal do Rio de Janeiro (UFRJ) e Rita Leal Paixão, Universidade Federal Fluminense (UFF), aponta para a necessidade de uma formação crítica do biólogo. Para tal, as autoras defendem a necessidade da disciplina "bioética" como disciplina obrigatória no curso de Ciências Biológicas, a partir da análise detalhada dos projetos pedagógicos dos cursos de graduação. Por fim, Bertti e Paixão afirmam a importância de revisão dos currículos para uma formação menos especista e, portanto, mais qualificada sobre questões ambientais.

O terceiro bloco congrega quatro artigos que dialogam com diferentes perspectivas do discurso ambiental. Estas perspectivas perpassam pelas práticas comunitárias de mulheres e pela construção da representação do "buen vivir" equatoriano, na mesma medida em que propõem reflexões a partir dos conceitos de subjetividades e estética neoliberal associados ao ambiente. Deste modo, o décimo artigo deste número da Revista Espaço do Currículo (REC), com o título PARTICIPAÇÃO COMUNITÁRIA: outras epistemologias, de autoria de Rita de Cássia Fraga Machado -Universidade do Estado do Amazonas (UEA)-, traz para o debate os povos da Floresta Nacional de Tefé (Flona-Tefé), interior do Amazonas. Para a autora, o termo comunidade ocupa um lugar de destaque na vida dos habitantes da floresta; ou seja, quase tudo se constrói por meio das comunidades e de forma comunitária. A autora ressalta que a participação comunitária e política feminina vêm aumentando nos últimos anos, principalmente devido ao acesso à educação, à formação e ao desejo de implementação de políticas públicas. Entre os principais resultados, a autora dar ênfase as motivações e a satisfação da participação dessas mulheres na esfera pública.

Os ventos do oceano pacífico nos trazem o texto CONVENTO ECO-EMPREENDE: um projeto comunitário de Educação Socioambiental para o empoderamento, na sociedade do Bem Viver do Equador, apresentado por Byron David Cevallos-Trujillo, Laura Terreros-Bejarrano e Javier Collado-Ruano -todos da Universidad Nacional de Educación do Ecuador (UNAE)-. Os autores destacam a necessidade de realizar ações que possibilitem o empoderamento das pessoas e das suas comunidades, para avançar em sentido de uma sociedade do Bom Viver. Nesse sentido, enfatizam que o artigo surgiu enquanto resultado de uma pesquisa que propõe uma experiência ecopedagógica, a qual constitui uma alternativa comunitária de processos da educação socioambiental. A partir desta experiência, concretizam a construção de um horto agroecológico e a criação de processos de empreendedorismo solidário. Para os autores, os principais resultados evidenciam que educação socioambiental requer diálogos de saberes e, por meio deles, a integração de conhecimentos científicos com a sabedoria ancestral das comunidades.

Na pauta da crise socioambiental, a pesquisadora Maristela Barenco Corrêa de Mello -Universidade Federal Fluminense (UFF)- propõe diferentes reflexões com o texto EDUCAÇÃO, CURRíCULO E MEIO AMBIENTE: fábrica ou ateliê de subjetividades?. No artigo, a autora destaca a insuficiência epistemológica de conceitos e de sentidos potentes em Educação Ambiental, na mesma medida em que ressalta a necessidade de estarmos atentos à reprodução das lógicas hegemônicas. Para tanto, traz para o debate a temática da Subjetividade, enquanto elemento que atravessa o discurso ambiental e o currículo. Logo, estabelece diferenciações desse atravessamento; ou seja, ora configurando em modos de subjetivação, na perspectiva de uma fábrica; ora configurando em modos de singularização, na perspectiva de um ateliê. Na argumentação teórica, a autora estabelece diálogos com Félix Guattari e Suely Rolnik, na qual os conceitos trabalhados vão no sentido de modos de singularização da subjetividade. Enquanto prática, a autora resgata uma experiência vivida com o grupo de jovens Filhos da Terra, cujo objetivo era fortalecer a perspectiva da Arte-Cidadania e Ecologia, com jovens de comunidades vulneráveis economicamente.

O texto A ESTÉTICA NEOLIBERAL DA NOVA RAZÃO DO MUNDO CAPITALISTA: educando o indivíduo competitivo, apresentado por Wagner Valente dos Passos e Carlos Roberto da Silva Machado -Instituto Federal de Educação, Ciências e Tecnologia Sul-Rio-Grandense (IFSUL) e Universidade Federal do Rio Grande (FURG), respectivamente-, oferece aos leitores a possibilidade de pensar e refletir com a hipótese de ser o capitalismo um regime estético. Os autores sustentem a argumentação no entendimento de que a 
manutenção e a sustentação da "partilha do sensível”, pautada em fundamentos políticos, na liberdade e na verdade da mercadorização, criam as bases para um contexto competitivo, todos contra todos como ideal. Diante disto levantam uma série de questionamentos, os quais perpassam pelo fazer pedagógico, pela dinâmica curricular capitalista e autoritária, pela responsabilidade da poluição e contaminação ambiental, entre outros. Todos esses questionamentos estão associados à possibilidade de um despertar solidário, para uma Educação Ambiental crítica e para a justiça social e ambiental.

O quarto bloco reuni dois artigos que apresentam contribuições diferenciadas ao campo epistemológico ambiental, especialmente quando estabelecem interseções entre ética ambiental e Educação em Direitos Humanos (EDH); sexualidade e ecologia, currículo e crianças vivendo com HIV (Human Immunodeficiency Virus). Nesse sentido, o décimo quarto artigo deste número da Revista Espaço do Currículo (REC), sob o título EDUCAÇÃO E(M) DIREITOS HUMANOS E BNCC: competências socioemocionais e ética ambiental, proposto por Daniela Rosendo e Fernanda Brandão Lapa -Universidade Federal de Santa Catarina (UFSC) e Universidade de Joinville (UNIVILLE), nesta ordem-, defende que o direito à educação deve abranger o desenvolvimento humano. As autoras recorrem à Base Nacional Comum Curricular (BNCC), para destacar a necessidade de resguardar as especificidades regionais e, assim, inserir a ética ambiental. Tal ética deve ser compreendida como um elemento fundamental, na medida em que a consideração moral da natureza é necessária para estabelecer relações sustentáveis, inclusivas e solidárias e, assim, garantir uma perspectiva de justiça socioambiental voltada à garantia de direitos fundamentais.

O último artigo desta sessão temática da Revista Espaço do Currículo (REC), com o título UMA CRIANÇA CAÍDA NO CHÃO: contaminação e acoplamentos virais em currículos, de autoria de Thiago Ranniery Moreira de Oliveira e de Luan Carpes Barros Cassal -Universidade Federal do Rio de Janeiro (UFRJ) e Universidade Federal Fluminense (UFF), respectivamente-, convida-nos a refletir sobre a temporalidade da reprodução sexual e a relacionalidade social. Os autores destacam, em suas análises, o campo de possibilidades matizado por graus de incerteza e pânico, explorando as dimensões da contaminação dentro um panorama mais amplo das políticas ecológicas. Inspirados nos debates sobre biopoder, Ranniery e Luan propõem um experimento narrativo a partir de acidentes de crianças com HIV em escolas, no qual a iminência de contaminação dos corpos nos currículos convida a pensar os entrelaçamentos entre vida e morte e vida e não-vida.

O quinto e último bloco deste número é formado por cinco artigos e uma resenha, oriundos da demanda contínua da Revista Espaço do Currículo (REC). Neste bloco os leitores terão acesso aos artigos e aos ensaios teóricos, cujos diálogos e debates envolvem temáticas e territorialidades diversas. Nesse sentido, o décimo sexto texto deste número, sob o título PRECISAMOS FALAR SOBRE CURRíCULO, é de autoria de Márden de Pádua Ribeiro -Faculdade de Ciências Sociais Aplicadas de Belo Horizonte (FACISA/BH). No ensaio, a autora propõe, de forma articulada, uma reflexão introdutória e atualizada sobre o complexo e polissêmico campo da educação, especialmente voltada ao campo curricular. Para tanto, problematiza as discussões que contemplam as vertentes tradicionais, críticas e pós-críticas do currículo. Sistematiza suas ideias sinalizando os limites e as potencialidades de tais vertentes a partir da ideia de híbridos teóricos, ancorando-se em Alice Casimiro Lopes e Antônio Flávio Barbosa Moreira. Uma tentativa de preencher uma lacuna que, na percepção da autora, está relacionada à disponibilidade de textos de caráter introdutório ao currículo, desde uma linguagem acessível aos interessados em geral.

Na sequência, apresentamos o artigo que tem como título POLÍTICAS CURRICULARES EM EDUCAÇÃO AMBIENTAL NO CURSO DE PEDAGOGIA: um estudo de caso na Universidade Federal de Rondônia (UNIR), proposto por Clarides Henrich de Barba e Elenice Cristina da Rocha Feza -Universidade Federal de Rondônia (UNIR) e Faculdades Associadas de Ariquemes (FAAR), nesta ordem-. Nesse texto, as autoras abordam o processo de inserção da temática ambiental no currículo do curso de Pedagogia. Entre os resultados mais relevantes, destacam que os docentes dos três campi da Universidade Federal de Rondônia (UNIR), lócus da pesquisa, Porto Velho, Guajará-Mirim e Ariquemes, realizam uma série de esforços voltados à abordagem da temática ambiental na perspectiva do ambiente físico. Entretanto, ressaltam a ausência de trabalhos que priorizem a dimensão ambiental pautada nas questões sociais, econômicas e culturais. 
ISSN 1983-1579

http://periodicos.ufpb.br/ojs2/index.php

Na pauta das políticas públicas educativas, o décimo oitavo artigo deste número da Revista Espaço do Currículo (REC), contempla a temática do REUNI E FLEXIBILIZAÇÃO CURRICULAR: o caso do curso de Pedagogia da UFAL-Campus Arapiraca. O artigo apresenta-se enquanto resultado das pesquisas realizadas por Lavoisier Almeida Santos -Secretaria Estadual de Educação/Sergipe (SEED/SE)- e, portanto, tem como finalidade estabelecer uma reflexão sobre a experiência formativa da primeira turma do curso de Pedagogia da Universidade Federal de Alagoas (UFAL), Campus Arapiraca. Para o autor do texto, o Programa de Expansão e Reestruturação das Universidades Federais (REUNI), obedecendo aos princípios economicistas, expandiu a educação superior pública aproveitando, da melhor forma possível, as estruturas física e humana das universidades federais. Deste modo, oferecendo aos estudantes de graduação, receptores deste programa, um itinerário formativo diferenciado.

Ainda no campo das políticas públicas, a sequência deste número da revista contempla o artigo POLÍTICAS CURRICULARES E EJA: a luta pela significação de gênero no contexto da prática docente, proposto por Rafael Ferreira de Souza Honorato, Maria Zuleide da Costa Pereira -Universidade Federal da Paraíba (UFPB)- e Tarcísio Duarte da Costa -Instituto Federal de Educação, Ciência e Tecnologia da Paraíba (IFPB). O texto é produzido enquanto resultado de uma pesquisa realizada junto ao curso de especialização lato sensu em Gênero e Diversidade na Escola (GDE) na Universidade Federal da Paraíba. Nesse sentido, os autores destacam que o objetivo do trabalho está pautado em analisar como as relações de gênero estão expressas no currículo dos Centros Estaduais de Educação de Jovens e Adultos (CEJAs) da Cidade de João Pessoa/PB. Entre os principais resultados, percebem que, mesmo com todos os desafios inerentes ao ensino na EJA, há uma tímida preocupação dos(as) docentes da escola estudada com as problemáticas referentes às relações de poder que emanam das relações de gênero.

O último artigo deste quinto bloco, resultado da demanda contínua da Revista Espaço do Currículo (REC), presenteia-nos uma profunda discussão teórica, em formato de ensaio, com o título GRAXA-DEESTUDANTE: uma flor entre usos, releituras e re-existências, pensado por Carlos Eduardo Ferraço e Fabiano de Oliveira Moraes -ambos da Universidade Federal do Espírito Santo (UFES)-. O texto está organizado desde uma perspectiva cotidianista de currículo, no qual os autores estabelecem como objetivo provocar problematizações e produções de sentidos possíveis nos/dos/com os cotidianos escolares e culturas. Com esse propósito, recorrem as contribuições teóricas, sobretudo no campo da educação, dos estudos em cotidianos e da filosofia, para apresentarem os possíveis usos e reinvenções de uma flor, pelos estudantes, como táticas, linhas de fuga, desterritorializações e jogos de poder, por meio de reinvenções potentes diante de normas escolares rígidas que materializam linhas molares em mecanismos de controle e vigilância.

Também como resultado da demanda contínua da Revista Espaço do Currículo (REC), Aldarosa Cartaxo, Dougllas Pierre e Letícia Ramos -todos da Universidade Federal da Paraíba (UFPB)- brindam aos leitores a resenha crítica da obra A GRAMÁTICA DO TEMPO: para Uma Nova Cultura Política, de Boaventura de Sousa Santos. Para os autores da resenha, nesta obra, Boaventura consolida anos de pesquisa e sua aproximação com a perspectiva pós-colonial e, deste modo, destaca o caráter coletivo da construção dos textos que, segundo ele, sintetiza sua busca antiga por um "novo senso comum". Igualmente, destacam que "A Gramática do tempo" se constitui como uma importante contribuição para o campo da educação e dos movimentos de resistência contra-hegemônicos, para o campo pós-colonial, pois além de evidenciar o empoderamento dos indivíduos invisibilizados pela hegemonia, instrumentaliza as diversas investigações no campo da educação.

Propor, reunir os textos e apresentar esta sessão temática que tem como título QUATRO DÉCADAS DE INSTITUCIONALIZAÇÃO DO DISCURSO AMBIENTAL: lógicas integrativas e restaurativas em currículos educativos, situa-nos em diferentes epistemologias do discurso ambiental. Epistemologias estas que, desde uma mirada integrativa, busca dialogar com diferentes sujeitos, temáticas e territorialidades, principalmente com aquelas que historicamente estiveram às margens dos panoramas nacionais de pesquisas. Entre elas podemos destacar o caso de crianças com HVI, das mulheres da floresta, da natureza e dos docentes na 
Amazônia, dos saberes e práticas ancestrais indígenas, dos conflitos históricos de acesso e utilização das unidades de conservação ambiental e, sobretudo, dos animais não-humanos.

Por sua vez, desde a lógica restaurativa, neste caso compreendida a partir da ancestralidade dos povos pindorâmicos, a proposta desse número da Revista Espaço do Currículo (REC) busca, no âmbito dos campos científicos do currículo e ambiental, restaurar, de alguma forma, a dignidade dos coletivos anteriormente citados frente às violências e às injustiças epistêmicas produzidas secularmente. Desse modo, confrontar os processos de violência, invisibilidade, precariedade, subalternidade e negação de direitos aos quais esses grupos sofrem diariamente. Por estas e outras razões, agradecemos às pesquisadoras e aos pesquisadores por aceitarem o desafio de pensar, conjuntamente, o discurso ambiental e seus desdobramentos em sua integração aos currículos desde outras lógicas epistemológicas. Aos leitores, desse logo, desejamos uma excelente leitura.

\section{REFERÊNCIAS}

ANDRADE, F. M. R.; CARIDE, J. A. Educação Ambiental e formação docente na Amazônia brasileira: contextos universitários e realidades cotidianas. Revista Diálogo Educacional, Curitiba, v. 17, n. 55, p. 1598-1618, dez., 2017.

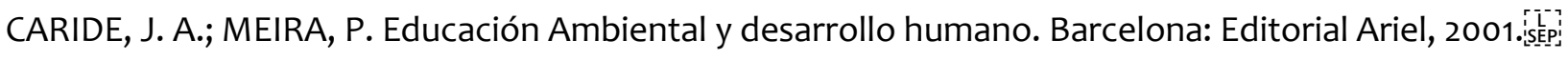

CARSON, R. Primavera Silenciosa. São Paulo: Editora Gaia Itda, 2010.

FOUCAULT, M. Hay que defender la sociedad. Madrid: Ediciones Akal, 2003. SẸp:

LEIS, H.R.; D’ AMATO, J.L. O ambientalismo como movimento vital: análise de suas dimensões histórica, ética e vivencial. In CAVALCANTI, C. (Org.). Desenvolvimento e Natureza: estudos para uma sociedade sustentável (pp. 77-103). São Paulo: Cortez, 1995.

MOLL, A. From sacracity to sustainability. Frankfurt: Peter Lang, 1991.

OLIVEIRA, F.A.G. O lugar do cuidado na construção de um veganismo crítico-interseccional. In OLIVEIRA, F.A.G. DIAS, M.C. (Org). Ética Animal: Um Novo Tempo (p.33-53). Rio de Janeiro: Livros llimitados, 2018.

REIGOTA, M. A floresta e a escolar: por uma educação ambiental pós-moderna. 4. ed. São Paulo: Cortez, 2011.

SAMPAIO, S. M.; GUIMARÃES, L. B. O dispositivo da sustentabilidade: pedagogias no contemporâneo. Perspectiva, v. 30, n. 2, p. 395-409, 2012.

SILVA, T. T. Documentos de identidade: uma introdução as teorias do currículo. 3. ed. Belo Horizonte: Autêntica: 2011. 